\title{
AGE VARIATIONS IN THE PROPERTIES OF HUMAN TIBIAL TRABECULAR BONE
}

\author{
MING DING， MICHEL DALSTRA， CARL C. DANIELSEN，JESPER KABEL， IVAN HVID， FRANK LINDE
}

From Aarhus University Hospital, Aarhus, Denmark

We tested in compression specimens of human proximal tibial trabecular bone from 31 normal donors aged from 16 to 83 years and determined the mechanical properties, density and mineral and collagen content.

Young's modulus and ultimate stress were highest between 40 and 50 years, whereas ultimate strain and failure energy showed maxima at younger ages. These age-related variations (except for failure energy) were non-linear.

Tissue density and mineral concentration were constant throughout life, whereas apparent density (the amount of bone) varied with ultimate stress. Collagen density (the amount of collagen) varied with failure energy. Collagen concentration was maximal at younger ages but varied little with age.

Our results suggest that the decrease in mechanical properties of trabecular bone such as Young's modulus and ultimate stress is mainly a consequence of the loss of trabecular bone substance, rather than a decrease in the quality of the substance itself. Linear regression analysis showed that collagen density was consistently the single best predictor of failure energy, and collagen concentration was the only predictor of ultimate strain.

J Bone Joint Surg [Br] 1997;79-B:995-1002.

Received 23 December 1996; Accepted after revision 29 May 1997

M. Ding, MD, Research Fellow

M. Dalstra, PhD, Associate Professor

J. Kabel, MD, Research Fellow

I. Hvid, MD, DMSci, Professor

F. Linde, MD, DMSci, Consultant Orthopaedic Surgeon

Orthopaedic Research Laboratory, Aarhus University Hospital ( $\mathrm{KH})$

Kommunehospital, Building 1A, DK-8000, Aarhus C, Denmark.

C. C. Danielsen, MD, Associate Professor

Department of Connective Tissue Biology, Institute of Anatomy, University of Aarhus, DK-8000 Aarhus C, Denmark.

Correspondence should be sent to Dr M. Ding.

(C)1997 British Editorial Society of Bone and Joint Surgery

0301-620X/97/67538\$2.00

VOL. 79-B, No. 6, NOVEMBER 1997
There have been many studies on the mechanical and physical properties of trabecular bone and their mutual relationships. ${ }^{1-10}$ They have also been described in relation to age. ${ }^{11-14}$ Generally, it has been found that Young's modulus, failure energy and apparent ash density are inversely and linearly correlated with age. All these studies have focused mainly on central vertebral trabecular bone although one by Lindahl ${ }^{12}$ included tibial trabecular bone. $\mathrm{He}$ found that the elastic modulus and ultimate stress were inversely correlated with age, but he used dried defatted specimens, a method of preparation that tends to alter the mechanical properties. ${ }^{1}$ The use of wet, non-defatted specimens has been found to give better representation of the in vivo mechanical properties. There have therefore been no general conclusions regarding age-related variations in the mechanical properties of peripheral trabecular bone.

Several studies have been made on age-related variations in human cortical bone. ${ }^{2,15-17}$ Currey ${ }^{2}$ showed that the elastic modulus and bending strength both increased until about 30 years and declined thereafter. McCalden et $\mathrm{al}^{17}$ reported that strength, strain and failure energy were inversely and linearly correlated with age.

The contribution of the two major components of bone, mineral and collagen, to the mechanical properties has been studied in cortical bone but has not been fully elucidated. The results of Burstein et $\mathrm{al}^{18}$ indicate that strength and elastic stiffness depend on the mineral content, but that the plasticity of bone is a function of the properties of collagen. The relative importance of collagen and mineral in determining the mechanical properties of trabecular bone has attracted little attention despite many investigations on apparent density and apparent ash density in relation to age. $^{13,14,19}$ We could find no published studies on the agerelated variation in collagen density, one major component of trabecular bone.

Our aims were therefore: 1) to investigate the normal age-related variations in the mechanical properties, composition and physical properties of peripheral (tibial) trabecular bone; 2) to examine correlations between them, especially the relationship between collagen, mineral and mechanical properties; and 3) to compare our findings with data from the literature. 


\section{MATERIALS AND METHODS}

Over a period of three years, 31 human proximal tibiae were taken from 31 donors aged between 16 and 83 years. There were five women and 26 men; all were Caucasian and were free from macroscopic pathological changes. They had all died suddenly from traumatic or acute disease, and had been active with no history of musculoskeletal disease. None had been immobilised for more than two weeks before death.

Seven cylindrical trabecular bone specimens were obtained from standardised locations in the medial condyle and six from the lateral condyle from each tibia, ${ }^{20}$ giving a total of 403 specimens.

Specimen preparation. All the specimens were drilled out of frozen bone using a trephine with an inner diameter of $7.5 \mathrm{~mm}$. The orientation of the cylindrical specimens was such that the longitudinal axis of the tibia corresponded to that of the cylinder. They were cut $1 \mathrm{~mm}$ beneath the subchondral bone plate at the distal end to a measured length of $7.5 \mathrm{~mm}$ using an EXAKT-Cutting Grinding System (EXAKT Apparatenbau, Norderstedt, Germany) and a LEITZ Saw Microtome 1600 (Ernst Leitz Wetzlar GmbH, Wetzlar, Germany).

During preparation or testing, eight specimens were damaged and were excluded leaving 395 specimens for non-destructive testing. Half of these $(n=198)$ were randomly selected for destructive testing, but operating failures during testing resulted in another 15 being lost, leaving 183. All the specimens were stored frozen in physiological saline in sealed plastic tubes at $-20^{\circ} \mathrm{C}$ until testing.

After mechanical testing, four specimens from each knee (two from the medial and two from the lateral condyle) were randomly selected for the measurement of apparent density, tissue density, porosity, collagen content and mineral content.

Compressive testing. The specimens were placed at room temperature for two hours in physiological saline before testing and were kept moist during the experiment. The mechanical tests were performed on an Instron materials testing machine (Model 4302, Instron Ltd, High Wycombe, $\mathrm{UK}$ ), using a $1 \mathrm{kN}$ load cell and a static strain-gauge extensometer (Model 2601-20, Instron Ltd) attached to the testing column close to the specimen. The testing columns with polished ends were lubricated with low-viscosity mineral oil to reduce the effect of friction. ${ }^{8}$ The testing machine was computer-controlled by Testpoint console software (Testpoint, Capital Equipment Co, Burlington, Massachusetts) which also handled force and deformation data collection. The force-deformation data were converted to stress and strain data using the cross-sectional area of the specimens for normalisation of load to stress and the original length of the specimens for normalisation of deformation to strain.

At least ten preconditioning cycles were performed between a preload of $3 \mathrm{~N}$ and a strain of 0.006 to reach a viscoelastic steady state before the final test was performed. ${ }^{20}$ Only the actual test data were collected for analysis. Young's modulus (stiffness) was obtained from non-destructive testing. Ultimate stress, ultimate strain and failure energy (energy absorption to failure) were obtained from destructive testing, using a strain rate of $0.002 / \mathrm{sec}$ and preceded by mechanical conditioning as used for nondestructive testing (Fig. 1).

Density, volume fraction, collagen and mineral measurements. After testing the marrow was removed from the specimens by air jet and tap water. The specimens were then defatted in a 1:1 mixture of alcohol and acetone for 48 hours, cleaned once more by air jet and evaporated at room temperature for 24 hours before being freeze-dried. The dry weight (DW) of the freeze-dried specimens was recorded. To determine the tissue density $\left(\rho_{\text {tiss }}\right)$, each sample was rehydrated under vacuum in Ringer's solution adding a wetting agent (Pervitro 75\%) and the submerged weight $\left(\mu_{\mathrm{s}}\right)$ of the sample was recorded in a Mettler AT250 balance (Mettler Instruments AG, Greifensee, Switzerland) equipped with a density determination kit. Determination of submerged weight and dry weight was repeated once. From the mean weights, the apparent density $\left(\rho_{\text {app }}\right)$ was calculated from the dry weight of the defatted specimen divided by its original volume, and the tissue density was calculated as:

$$
\rho_{\text {tiss }}=\mathrm{DW} * \rho_{\mathrm{L}} /\left(\mathrm{DW}-\mu_{\mathrm{s}}\right)
$$

where $\rho_{\mathrm{L}}=1.00 \mathrm{~g} / \mathrm{cm}^{3}$ is the density of the submersion liquid. Porosity was derived as $\left(1-\rho_{\mathrm{app}} / \rho_{\mathrm{tiss}}\right)$, and volume fraction as (1-porosity).

The specimens were divided into four pieces for duplicate determinations of ash and collagen content. To account

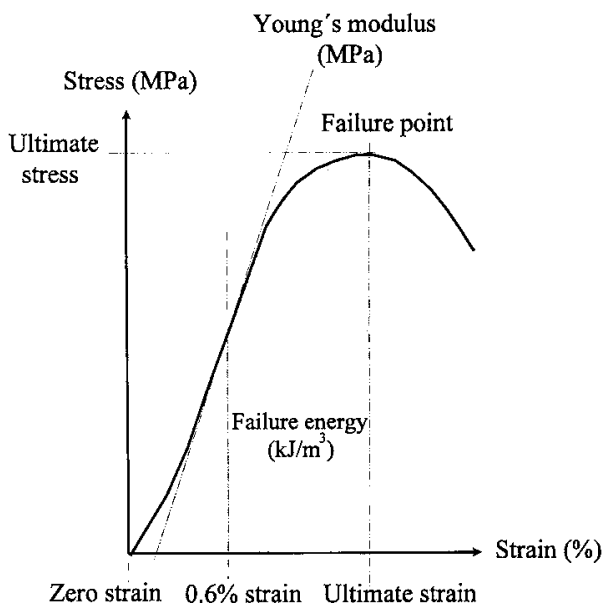

Fig. 1

A typical stress-strain curve from a destructive test Ultimate stress and ultimate strain were derived from the first maximum of the curve. Young's modulus was determined as the tangent to the point on the loading curve intersecting the $0.6 \%$ strain line, and failure energy as the area underneath the compression curve between zero strain and ultimate strain. 
for inhomogeneity of the specimens, we performed duplicate determinations of ash and hydroxyproline on both a distal and a proximal piece (Fig. 2).

The collagen content of the specimens was estimated by measuring hydroxyproline, assuming a content of hydroxyproline in collagen of $13.4 \%(\mathrm{w} / \mathrm{w}){ }^{21}$ After hydrolysis of the specimens in $6 \mathrm{M} \mathrm{HC} 1$ at $100^{\circ} \mathrm{C}$ for 16 hours, hydroxyproline was estimated according to the procedure of Woessner $^{22}$ with a slight modification of the concentration of reagents ${ }^{23}$ as described by Danielsen and Andreassen. ${ }^{24}$ The collagen (tissue) concentration was calculated to be the amount of collagen divided by the dry weight, and the collagen (apparent) density was the collagen weight divided by specimen volume. The bone specimens were ashed in a muffle oven at $100^{\circ} \mathrm{C}$ for 2 hours and $580^{\circ}$ for 18 hours, and the dry weight of the ash determined. The mineral concentration was the amount of mineral divided by the dry weight, and the apparent ash density was the mineral weight divided by the specimen volume.

Statistical analysis. The specimens were divided into young (16 to 39 years), middle (40 to 59 years) and old (60 to 83 years) age groups. All the statistical analyses (SPSS; SPSS Inc, Chicago, Illinois) were based on the entire data set, and the mean value for each tibia was used in analyses of age-related variations (each individual represented by one set of values). For comparison of properties, only the specimens which had been used for the determination of both mechanical and physical/compositional properties were included in the analysis.

One-way analysis of variance (ANOVA) was used to compare the properties in the three different age groups. These data were first checked for equal variance by the Levene test, and for normality by the Omnibus test. If the F-test showed a significant level, a multiple comparison was made by the Bonferroni test to find the difference between groups. If the F-test showed no significant level, ANOVA was further performed based on age groups divided into decades to test for any significant difference among decades. Since there was only one tibia in the first decade group, this tibia was included in the second decade, defined as the younger age group. As there were unequal variances (in the different decades), tissue density was logarithmically transformed to obtain equal variances.

Linear regression analyses were used to assess the association between mechanical and physical properties. Stepwise multiple regression analyses were used to assess the associations between one mechanical property (Young's modulus, ultimate stress, ultimate strain or failure energy) as a dependent variable and seven physical properties (tissue, collagen, apparent and apparent ash densities, collagen and mineral concentrations, volume fraction) as independent variables. The paired $t$-test was used to compare the properties between the medial and lateral condyles.

The linearity of the properties in relation to age was first checked. If they showed non-linear relationships with age, then polynomial regression (second-degree fit) was used to

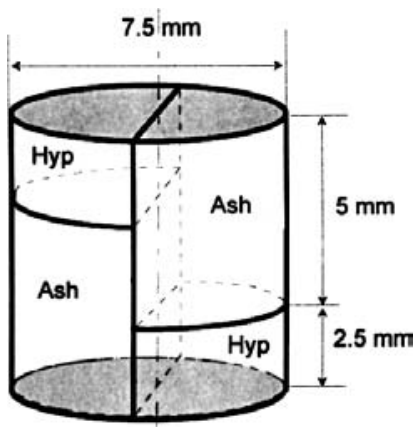

Fig. 2

\begin{abstract}
Diagram showing how specimens were cleaved. Two minor pieces (one proximal and one distal) were used for hydroxyproline (Hyp) determination, and two major pieces (one proximal and one distal) for the determination of ash weight.
\end{abstract}

describe the variations. The determination coefficients $\left(\mathrm{r}^{2}\right)$ were used to explain the proportional variation due to either linear regression or curve fitting. A $p$ value $<0.05$ was considered to be significant.

\section{RESULTS}

Age-related variations. Variations in the mechanical and physical properties in the three age groups and in decades were analysed based on ANOVA (Table I).

Young's modulus (Fig. 3) showed an initial increase but no significant difference between the young and middle age groups, but was significantly larger in the middle age group compared with the old age group $(\mathrm{p}<0.001)$ with a maximum at 40 to 50 years. There was a significant decrease after 60 years $(\mathrm{p}<0.001)$.

Ultimate stress showed no significant difference between the young and the middle age groups, and was lowest in the old age group $(\mathrm{p}<0.001)$. Further analysis of the data in decades showed that this value was constant between 30 and 59 years $(p=0.76)$, and declined after 60 years $(\mathrm{p}<0.001)$.

Ultimate strain in the young age group proved to be significantly greater than in the old age group $(\mathrm{p}<0.05)$, with no difference between the young and middle age groups. Analysis of the data in decades showed that this value was maximal in the younger age group $(\mathrm{p}<0.05)$, and did not vary significantly in the other age groups $(\mathrm{p}=0.17)$.

Failure energy was lowest in the old age group $(\mathrm{p}<0.001)$ and showed no significant difference between young and middle age groups. Analysis of the data in decades, however, showed that it was largest in the younger age group $(\mathrm{p}<0.001)$, constant between 30 and 59 years $(\mathrm{p}=0.08)$, and declined beyond 60 years $(\mathrm{p}<0.001)$.

Tissue density (Fig. 4) showed no significant variation with age $(p=0.88)$. Analysis in decades showed it to be 
Table I. Age-related variations (mean \pm SD) in the mechanical and physical/compositional properties overall and in the three age groups (see text)

\begin{tabular}{lclccc}
\hline Measurement & Overall & p value & Young & Middle & Old \\
\hline Mechanical & & & & \\
$\quad$ Young's modulus $(\mathrm{MPa})$ & $635 \pm 386$ & $<0.001$ & $654 \pm 304$ & $829 \pm 422$ & $613 \pm 319$ \\
Ultimate stress $(\mathrm{MPa})$ & $8.82 \pm 3.50$ & $<0.001$ & $10.6 \pm 3.64$ & $9.86 \pm 2.56$ & $7.27 \pm 3.04$ \\
Ultimate strain $(\%)$ & $2.22 \pm 0.67$ & $<0.05$ & $2.48 \pm 0.64$ & $2.12 \pm 0.64$ & $2.05 \pm 0.60$ \\
Failure energy $\left(\mathrm{kJ} / \mathrm{m}^{3}\right)$ & $110 \pm 52$ & $<0.001$ & $145 \pm 61$ & $112 \pm 36$ & $87 \pm 41$ \\
Physical/compositional & & & & $2.18 \pm 0.10$ \\
Tissue density $\left(\mathrm{g} / \mathrm{cm}^{3}\right)$ & $2.20 \pm 0.07$ & 0.88 & $2.21 \pm 0.05$ & $2.20 \pm 0.07$ \\
Apparent density $\left(\mathrm{g} / \mathrm{cm}^{3}\right)$ & $0.46 \pm 0.12$ & $<0.001$ & $0.52 \pm 0.10$ & $0.51 \pm 0.11$ & $0.40 \pm 0.10$ \\
Mineral concentration $(\%)$ & $66.4 \pm 2.5$ & 0.87 & $66.4 \pm 1.4$ & $66.6 \pm 3.4$ & $66.5 \pm 2.5$ \\
Apparent ash density $\left(\mathrm{g} / \mathrm{cm}^{3}\right)$ & $0.31 \pm 0.08$ & $<0.001$ & $0.34 \pm 0.07$ & $0.34 \pm 0.08$ & $0.27 \pm 0.07$ \\
Collagen concentration $(\%)$ & $25.4 \pm 1.4$ & 0.06 & $25.7 \pm 1.2$ & $24.9 \pm 1.0$ & $25.3 \pm 1.2$ \\
Collagen density $\left(\mathrm{g} / \mathrm{cm}^{3}\right)$ & $0.12 \pm 0.03$ & $<0.001$ & $0.13 \pm 0.03$ & $0.13 \pm 0.03$ & $0.10 \pm 0.03$ \\
Volume fraction $(\%)$ & $21.2 \pm 5.6$ & $<0.001$ & $23.4 \pm 4.6$ & $23.4 \pm 5.7$ & $18.4 \pm 5.0$ \\
\hline
\end{tabular}

very constant $(\mathrm{p}=0.53)$.

Apparent density was lowest in the old age group $(\mathrm{p}<0.001)$ with no significant difference between young and middle age groups. Analysis in decades showed that it was constant until the age of 59 years $(p=0.87)$, followed by a steady decline $(\mathrm{p}<0.001)$.

Apparent ash density showed the same tendency as apparent density. These two parameters were strongly correlated $\left(r^{2}=0.97, p<0.001\right)$ in accordance with the small variation in tissue density.

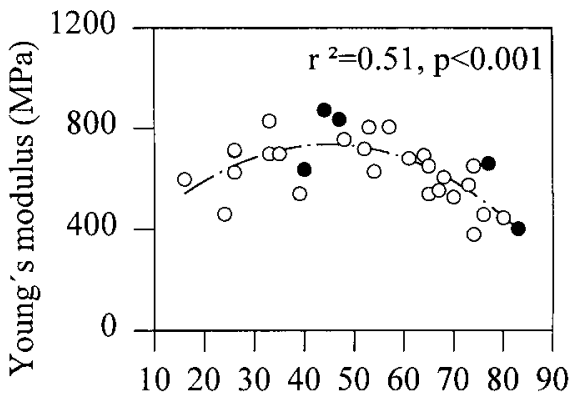

Age (years)

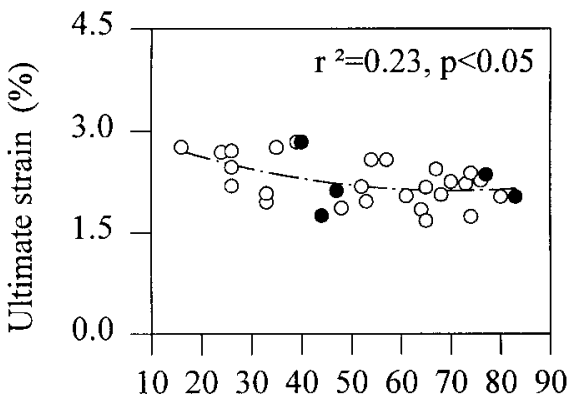

Age (years)
Mineral concentration showed no significant variation with age $(p=0.87)$ and analysis in decades showed that, like tissue density, it was very constant $(p=0.81)$.

Volume fraction showed a tendency similar to apparent density and also correlated strongly with apparent density $\left(r^{2}=0.96, p<0.001\right)$ and apparent ash density $\left(r^{2}=0.90\right.$, $\mathrm{p}<0.001)$.

Collagen concentration showed no significant difference in the three age groups, but analysis in decades showed that it was highest in the younger age group $(p<0.005)$ and

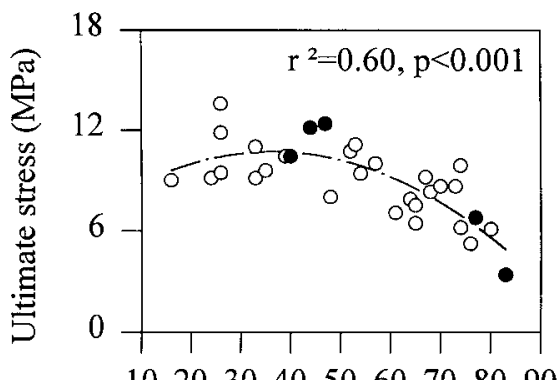

102030405060708090

Age (years)

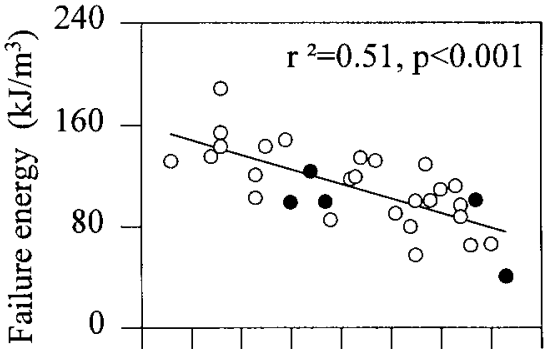

102030405060708090

Age ( years)

Fig. 3

The mechanical properties of tibial trabecular bone $v$ age, using the mean value of each knee. Due to the nonlinear relationship of Young's modulus, ultimate stress and ultimate strain with age, a second-degree polynomial fit (dash line) was used $\left(==\right.$ female $\left(n_{1}=5\right), \bigcirc=$ male $\left.\left(n_{2}=26\right)\right)$. The determination coefficients $\left(r^{2}\right)$ and $p$ values were derived from linear or second-degree polynomial regression. 


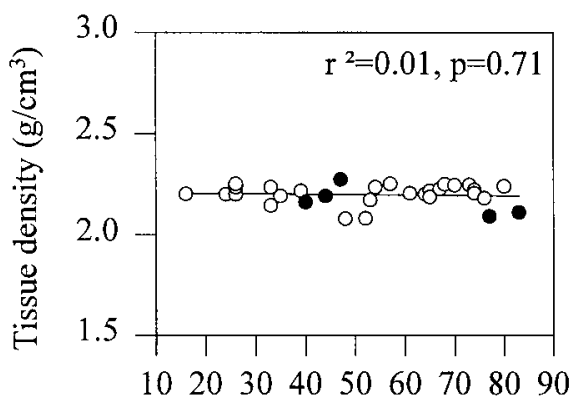

Age ( years )

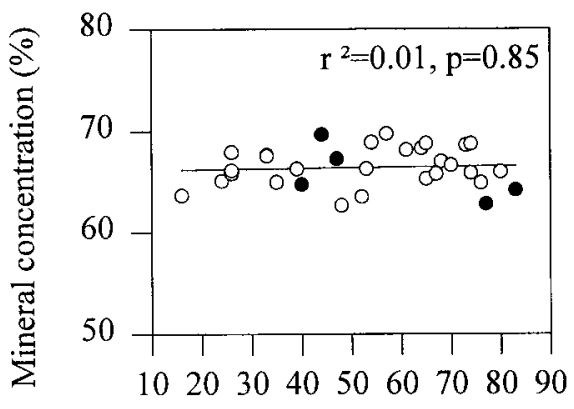

Age ( years )

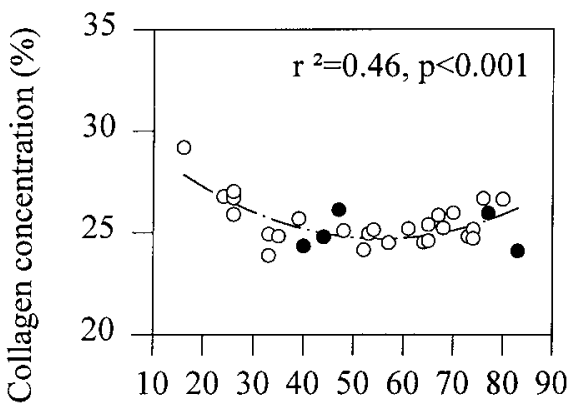

Age ( years )

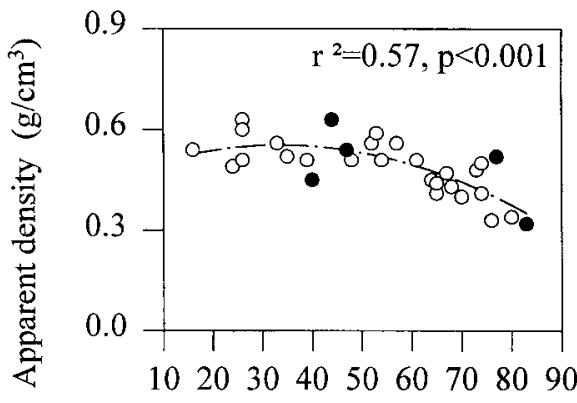

Age (years)

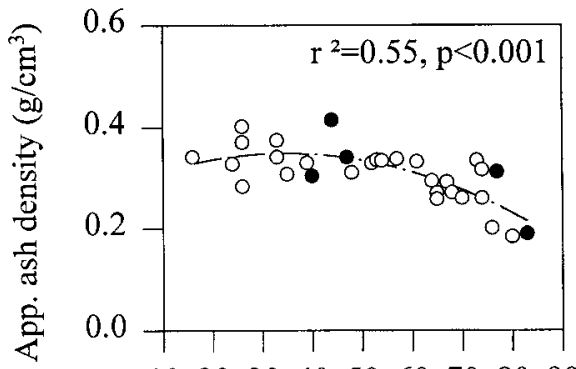

$\begin{array}{lllllllll}10 & 20 & 30 & 40 & 50 & 60 & 70 & 80 & 90\end{array}$

Age ( years )

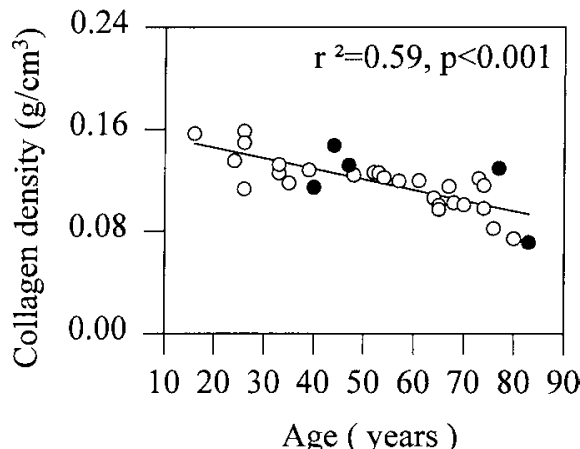

Fig. 4

The physical properties of tibial trabecular bone $v$ age, using the mean value of each knee. Due to the non-linear relationship of collagen concentration, apparent density and apparent ash density with age, a second-degree polynomial fit (dash line) was used $\left(=\right.$ female $\left(n_{1}=5\right), \bigcirc=$ male $\left.\left(n_{2}=26\right)\right)$. The determination coefficients $\left(\mathrm{r}^{2}\right)$ and $\mathrm{p}$ values were derived from linear or second-degree polynomial regression.

constant thereafter throughout life $(p=0.56)$. Collagen density was lowest in the old age group $(p<0.001)$ and there was no significant difference between young and middle age groups. It was highest in the younger age group $(\mathrm{p}<0.001)$, constant between 30 and 59 years $(\mathrm{p}=0.65)$, and followed by a significant decline beyond 60 years $(p<0.001)$. The existence of a maximum value of collagen density in the younger age group was different from what was found for apparent density, apparent ash density and volume fraction, although collagen density showed strong correlations with these parameters $\left(r^{2}=0.94, r^{2}=0.88\right.$, $\mathrm{r}^{2}=0.90$, respectively; $\left.\mathrm{p}<0.001\right)$.

Relationships between physical/compositional parameters and mechanical properties. The relationships between physical/compositional parameters and mechanical properties are based on linear regression analysis and are summarised in Table II. Stepwise multiple linear regression analysis showed that collagen density correlated best with failure energy, whereas apparent density and apparent ash density showed the second best correlation with failure energy. Apparent ash density and apparent density showed the best correlation with ultimate stress. Apparent ash density showed the best correlation with Young's modulus. Collagen concentration only correlated with ultimate strain.

Differences between medial and lateral condyles. The average values for the mechanical and physical properties of the specimens as well as the values for the medial and lateral condyles are shown in Table III. The average values of Young's modulus, ultimate stress, apparent density, apparent ash density, collagen density and volume fraction from the medial condyle were significantly larger (14\% to 
Table II. Linear regression analysis between physical/compositional parameters and mechanical properties

\begin{tabular}{|c|c|c|c|c|c|c|c|c|}
\hline & \multicolumn{2}{|c|}{ Young's modulus } & \multicolumn{2}{|c|}{ Ultimate stress } & \multicolumn{2}{|c|}{ Ultimate strain } & \multicolumn{2}{|c|}{ Failure energy } \\
\hline & $\mathbf{r}^{2}$ & p value & $\mathbf{r}^{2}$ & p value & $\mathbf{r}^{2}$ & p value & $\mathbf{r}^{2}$ & p value \\
\hline Tissue density & 0.002 & 0.82 & 0.02 & 0.41 & 0.07 & 0.15 & 0.04 & 0.19 \\
\hline Apparent density & 0.31 & $<0.001$ & 0.71 & $<0.001$ & 0.02 & 0.44 & 0.47 & $<0.001$ \\
\hline Mineral concentration & 0.09 & 0.09 & 0.03 & 0.34 & 0.005 & 0.70 & 0.01 & 0.58 \\
\hline Apparent ash density & 0.35 & $<0.001$ & 0.72 & $<0.001$ & 0.01 & 0.53 & 0.46 & $<0.001$ \\
\hline Collagen concentration & 0.08 & 0.13 & 0.0001 & 0.99 & 0.25 & $<0.005$ & 0.08 & 0.13 \\
\hline Collagen density & 0.22 & $<0.05$ & 0.66 & $<0.001$ & 0.07 & 0.15 & 0.54 & $<0.001$ \\
\hline Volume fraction & 0.28 & $<0.005$ & 0.65 & $<0.001$ & 0.007 & 0.64 & 0.40 & $<0.001$ \\
\hline
\end{tabular}

Table III. Mechanical and physical/compositional properties (mean \pm SD) of the medial and lateral condyles of tibial trabecular bone

\begin{tabular}{lcccc}
\hline Measurement & Medial condyle & Lateral condyle & Med-Lat & $\begin{array}{c}\text { p value } \\
(\mathbf{M} \boldsymbol{v} \mathbf{L})\end{array}$ \\
\hline Mechanical & & & & \\
$\quad$ Young's modulus $(\mathrm{MPa})$ & $708 \pm 402$ & $560 \pm 352$ & $144 \pm 225$ & $<0.001$ \\
Ultimate stress $(\mathrm{MPa})$ & $9.34 \pm 3.67$ & $8.22 \pm 3.21$ & $1.58 \pm 2.53$ & $<0.03$ \\
Ultimate strain $(\%)$ & $2.21 \pm 0.69$ & $2.24 \pm 0.66$ & $0.26 \pm 1.33$ & 0.76 \\
Failure energy $\left(\mathrm{kJ} / \mathrm{m}^{3}\right)$ & $115 \pm 55$ & $103 \pm 48$ & $14.6 \pm 37.7$ & 0.12 \\
Physical/compositional & & & & 0.09 \\
Tissue density $\left(\mathrm{g} / \mathrm{cm}^{3}\right)$ & $2.19 \pm 0.07$ & $2.21 \pm 0.07$ & $-0.02 \pm 0.06$ & $<0.001$ \\
Apparent density $\left(\mathrm{g} / \mathrm{cm}^{3}\right)$ & $0.50 \pm 0.11$ & $0.42 \pm 0.11$ & $0.08 \pm 0.08$ & 0.10 \\
Mineral concentration $(\%)$ & $66.0 \pm 2.5$ & $66.8 \pm 2.5$ & $-0.78 \pm 2.07$ & $<0.001$ \\
Apparent ash density $\left(\mathrm{g} / \mathrm{cm}^{3}\right)$ & $0.33 \pm 0.07$ & $0.28 \pm 0.07$ & $0.05 \pm 0.05$ & 0.75 \\
Collagen concentration $(\%)$ & $25.4 \pm 1.4$ & $25.5 \pm 1.3$ & $-0.10 \pm 1.29$ & $<0.001$ \\
Collagen density $\left(\mathrm{g} / \mathrm{cm}^{3}\right)$ & $0.13 \pm 0.03$ & $0.11 \pm 0.03$ & $0.02 \pm 0.02$ & $<0.001$ \\
Volume fraction $(\%)$ & $23.0 \pm 5.2$ & $19.2 \pm 5.3$ & $3.79 \pm 4.26$ & \\
\hline
\end{tabular}

$26 \%)$ than those from the lateral condyle $(\mathrm{p}<0.05$ to $\mathrm{p}<0.001)$. There were no substantial differences for ultimate strain, failure energy, tissue density, mineral concentration and collagen concentration between the condyles.

\section{DISCUSSION}

There have been several studies on the effects of storage and freezing of trabecular bone. ${ }^{25,26}$ Panjabi et al ${ }^{25}$ showed that long-term freezing of trabecular bone (up to 232 days) had no significant effect on the mechanical properties. More recently, Linde and Sørensen ${ }^{26}$ reported that freezing for 100 days did not change the stiffness, nor did repeated thawing, testing, and refreezing sequences. The effect of freezing for a longer time has not been examined. The mechanical properties of our material, however, did not seem to be affected by the time of storage as confirmed by bivariate regression analysis.

We used non-destructive tests to obtain Young's moduli from all specimens (13 specimens from each tibia) in order to obtain more accurate values. Those from non-destructive and destructive tests, however, were highly correlated $\left(\mathrm{r}^{2}=0.95, \mathrm{p}<0.001\right.$, both calculated at $0.6 \%$ strain $)$.

It has been reported that the tissue density for human trabecular bone is about $1.9 \mathrm{~g} / \mathrm{cm}^{3}$, and for cortical bone about $2.0 \mathrm{~g} / \mathrm{cm}^{3}{ }^{3.7}$ Our tissue density $\left(2.2 \mathrm{~g} / \mathrm{cm}^{3}\right)$ is slightly higher than these values probably due to differences in the methods of determination of dry weight. We used the freeze-drying method to determine dry weight to avoid considerable variations due to evaporation at room temperature. ${ }^{28}$ Since freeze-drying dehydrates specimens more thoroughly, the dry weight is lower and consequently tissue density is higher. We consider our results to be more accurate.

Previous studies have reported a significant decline in the ultimate stress of trabecular bone from vertebra, ${ }^{11-14}$ tibia, ${ }^{12}$ and calcaneus, ${ }^{14}$ a decline in the Young's modulus of trabecular bone from vertebra ${ }^{12,13}$ and tibia, ${ }^{12}$ and a decline in the failure energy from vertebra ${ }^{13}$ after 50 years of age (Table IV). Our results confirm these findings.

The values for Young's modulus for human tibial trabecular bone are mostly in a range from 200 to $900 \mathrm{MPa}$, for ultimate stress from 5.3 to $9.5 \mathrm{MPa}$, for ultimate strain from $2 \%$ to $2.7 \%$, and for failure energy from 30 to $170 \mathrm{~kJ} /$ $\mathrm{m}^{3.29}$ For human vertebral trabecular bone these values are 25 to $250 \mathrm{MPa}, 2$ to $4 \mathrm{MPa}, 2 \%$ to $2.7 \%$, and 40 to $90 \mathrm{~kJ} /$ $\mathrm{m}^{3}$, respectively. ${ }^{4,29}$

Our mechanical data are in the range of previous findings. Lindahl, ${ }^{12}$ however, reported extremely low values for stiffness and strength and an extremely high value for ultimate strain for human tibial trabecular bone compared with other findings (Table IV). These variations are probably due to the different protocols used in the preparation of specimens (dry defatted $v$ wet non-defatted), ${ }^{1}$ specimen geometry, ${ }^{1,30}$ preconditioning before actual mechanical testing, ${ }^{6}$ and anatomical location. ${ }^{4}$ The data therefore are not comparable. 
Table IV. Comparison of age-related mechanical properties of human trabecular bone

\begin{tabular}{|c|c|c|c|c|c|c|}
\hline \multirow[b]{2}{*}{ Authors } & \multirow{2}{*}{$\begin{array}{l}\text { Age } \\
\text { range } \\
(\mathrm{yr})\end{array}$} & \multirow[b]{2}{*}{ Topography $\left(\mathbf{n}_{1}, \mathbf{n}_{2}\right)^{*}$} & \multicolumn{4}{|c|}{ Typical mechanical data } \\
\hline & & & $\begin{array}{l}\text { Ultimate stress } \\
\text { (MPa) }\end{array}$ & $\begin{array}{l}\text { Ultimate strain } \\
(\%)\end{array}$ & $\begin{array}{l}\text { Young's modulus } \\
\text { (MPa) }\end{array}$ & $\begin{array}{l}\text { Failure energy } \\
\left(\mathbf{k J} / \mathbf{m}^{3}\right)\end{array}$ \\
\hline \multirow[t]{2}{*}{ Weaver \& Chalmers $^{14}$} & 10 to 90 & Vertebra $(137,137)$ & $3.1(0.4$ to 8$)$ & & & \\
\hline & & Calcaneus $(99,99)$ & $3.7(0.4$ to 10$)$ & & & \\
\hline Bell et $\mathrm{al}^{11}$ & 26 to 86 & Vertebra $(32,63)$ & $(0.7$ to 16$)$ & (1.8 to 8.9$)$ & & 0.44 \\
\hline \multirow[t]{6}{*}{ Lindahl $^{12}$} & 14 to 89 & Vertebra $(60,201)$ & & & & \\
\hline & & Male & $4.6(0.2$ to 11$)$ & $6.7\left(\epsilon_{\mathrm{y}}, 4\right.$ to 9$) \dagger$ & 56 (1 to 139$)$ & \\
\hline & & Female & $2.7(0.3$ to 7$)$ & $6.1\left(\epsilon_{\mathrm{y}}, 3\right.$ to 10$)$ & $35(5$ to 104$)$ & \\
\hline & & Tibia $(60,201)$ & & & & \\
\hline & & Male & $3.9(0.2$ to 6.7$)$ & $8.3\left(\epsilon_{\mathrm{y}}, 4\right.$ to 19$)$ & 35 (3 to 74$)$ & \\
\hline & & Female & $2.2(0.6$ to 5$)$ & $7\left(\epsilon_{\mathrm{y}}, 1.4\right.$ to 14$)$ & $23(1.4$ to 79$)$ & \\
\hline \multirow[t]{3}{*}{ Mosekilde et $\mathrm{al}^{13}$} & 15 to 87 & Vertebra $(42,84)$ & & & & \\
\hline & & Vertical & $2.5(0.8$ to 7$)$ & 7.4 & $67(10$ to 175$)$ & 89 (20 to 300$)$ \\
\hline & & Horizontal & $0.9(0.1$ to 2.7$)$ & 8.5 & $20(10$ to 70$)$ & $40(20$ to 100$)$ \\
\hline Ding et al (this series) & 16 to 83 & Tibia $(31,395 / 183 \neq)$ & $8.8(1.4$ to 19$)$ & $2.2(1.2$ to 4.6$)$ & $635(24$ to 2000$)$ & $110(21$ to 305$)$ \\
\hline
\end{tabular}

$* \mathrm{n}_{1}=$ number of donors; $\mathrm{n}_{2}=$ number of specimens

$\dagger \epsilon_{\mathrm{y}}=$ yield strain

₹ 395 specimens for Young's modulus, 183 specimens for ultimate stress, ultimate strain and failure energy

We expected failure energy to follow the course of Young's modulus, which showed an initial increase between 16 and 39 years, since these properties usually are well correlated. ${ }^{9}$ Failure energy showed a maximum between 16 and 29 years $(\mathrm{p}<0.001)$, which suggests that trabecular bone is tougher in the younger age group. This suggestion is supported by the finding that ultimate strain is highest in this group $(\mathrm{p}<0.05)$, and also agrees with values for cortical bone. ${ }^{16}$

Mosekilde et $\mathrm{al}^{13}$ found that from 20 to 80 years of age, ultimate stress, ultimate stiffness and failure energy of vertebral trabecular bone showed a linear decrease of $75 \%$ to $80 \%$ for vertical compression and $90 \%$ to $96 \%$ for horizontal compression. We found that age-related variations in mechanical properties except for failure energy could not be appropriately described by linear regression analysis for tibial trabecular bone. We therefore used polynomial regression (second-degree fit) to describe the relationship with age.

The ultimate strain of trabecular bone (from vertebra or tibia) has been reported either not to vary with age ${ }^{12}$ or to increase with age (from vertebra). ${ }^{13}$ We found that although ultimate strain was higher in the younger age group $(\mathrm{p}<0.05)$, it varied only slightly throughout life. This finding suggests that it is possibly the best parameter on which to base bone modelling. ${ }^{31,32}$ It is of note that our results showed ultimate strain to be significantly correlated with collagen concentration rather than densities.

Collagen density showed a strong correlation with apparent ash density and apparent density. They all showed a parallel decline after 50 to 60 years of age. These findings suggest that, despite the substance loss (density decline), the substance itself remains constant in composition as shown by the constant tissue density, mineral concentration and collagen concentration throughout adult life. The decrease in mechanical properties seems therefore to be mainly due to loss of bone substance, rather than a decrease in the quality of the substance itself. This result agrees with the finding for cortical bone. ${ }^{17}$

In addition to collagen, the bone matrix consists of approximately $10 \%$ non-collagenous organic components including proteoglycans which have been suggested to have some influence on the mechanical properties of bone tissue. Decorin, a small proteoglycan present in bone, is known to be closely associated with collagen ${ }^{33,34}$ and studies have shown a changed proteoglycan orientation after mechanical loading. ${ }^{35}$ Furthermore, proteoglycans bind interstitial fluid which is especially known to influence the mechanical properties of cartilage. $^{36}$ Similarly, bound water in organic bone matrix may influence the mechanical properties of bone. In our study therefore variation in the proteoglycan composition and quantity of the bone specimens tested may have contributed to the variation in mechanical parameters. This requires further investigation.

There have been several studies on the age-related variations in mechanical properties of cortical bone. ${ }^{2,16,17}$ McCalden et $\mathrm{al}^{17}$ found that ultimate stress, ultimate strain and failure energy of cortical bone decreased linearly by $5 \%, 9 \%$ and $12 \%$, respectively, per decade. It is of note that although ultimate strain in cortical bone decreased significantly with ageing, in trabecular bone there was a maximum in the younger age group which remained constant thereafter. We found Young's modulus of trabecular bone to vary significantly with age which differs from the findings of McCalden et $\mathrm{al}^{17}$ in which the modulus of cortical bone changed little with age. Our finding is in agreement with that of Currey and Butler ${ }^{16}$ who also showed that the elastic modulus and bending strength both increased with age until about 30 years and decreased thereafter.

McCalden et al $^{17}$ also reported the importance of agerelated changes in porosity in the decline in mechanical properties. Porosity accounted for $76 \%$ of the reduction in the ultimate stress of cortical bone. 
Both linear regression and stepwise multiple linear regression analyses showed that the collagen density was a better predictor in determining failure energy of trabecular bone than mineralisation, density and porosity. Collagen density alone can explain $54 \%$ of the variation of failure energy.

We conclude that the mechanical properties and apparent density, apparent ash density, collagen concentration, collagen density and volume fraction of human tibial trabecular bone have significant relationships with age. Age-related variations in Young's modulus, ultimate stress and ultimate strain, apparent density, apparent ash density and collagen concentration can be described by non-linear relationships. Trabecular bone is tougher in the younger age group. Tissue density and mineral concentration are found not to vary with age. Bone collagen, apparent density and apparent ash density and volume fraction all have significant influence on the mechanical properties. Collagen density was found to be the single best predictor of failure energy and collagen concentration to be the only predictor of ultimate strain.

The Danish Rheumatism Association (Gigtforeningen, Grant No. 233-949), the Orthopaedic Research Foundation, Aarhus University Hospital, and the Institute of Experimental Clinical Research, Aarhus University, Denmark are gratefully acknowledged for financial support. We wish to thank Eva Mikkelsen for skilful technical assistance.

Although none of the authors have received or will receive benefits for personal or professional use from a commercial party related directly or indirectly to the subject of this article, benefits have been or will be received but are directed solely to a research fund, educational institution, or other non-profit institution with which one or more of the authors is associated.

\section{REFERENCES}

1. Carter DR, Hayes WC. The compressive behavior of bone as a twophase porous structure. J Bone Joint Surg [Am] 1977;59-A:954-62.

2. Currey JD. Changes in the impact energy absorption of bone with age. J Biomech 1979;12:459-69.

3. Dalstra M, Huiskes R, Odgaard A, van Erning L. Mechanical and textural properties of pelvic trabecular bone. J Biomech 1993;26: 523-35.

4. Goldstein SA. The mechanical properties of trabecular bone: dependence on anatomic location and function. J Biomech 1987;20 1055-61.

5. Hvid I, Hansen SL. Trabecular bone strength patterns at the proximal tibial epiphysis. J Orthop Res 1985;3:464-72.

6. Hvid I, Bentzen SM, Linde F, et al. X-ray quantitative computed tomography: the relations to physical properties of proximal tibial trabecular bone specimens. J Biomech 1989;22:837-44.

7. Keaveny TM, Hayes WC. A 20-year perspective on the mechanical properties of trabecular bone. J Biomech Eng 1993;115 (4B):534-42.

8. Linde F, Hvid I. The effect of constraint on the mechanical behaviour of trabecular bone specimens. J Biomech 1989;22:485-90.

9. Linde F, Hvid I, Pongsoipetch B. Energy absorptive properties of human trabecular bone specimens during axial compression. J Orthop Res 1989;7:432-9

10. Linde F, Nørgaard P, Hvid I, Odgaard A, Søballe K. Mechanica properties of trabecular bone: dependency on strain rate. J Biomech 1991;24:803-9.

11. Bell GH, Dunbar O, Beck JS, Gibb A. Variations in strength of vertebrae with age and their relation to osteoporosis. Calcif Tissue Res 1967; 1:75-86.
12. Lindahl O. Mechanical properties of dried defatted spongy bone. Acta Orthop Scand 1976;47:11-9.

13. Mosekilde L, Mosekilde L, Danielsen CC. Biomechanical competence of vertebral trabecular bone in relation to ash density and age in normal individuals. Bone 1987;8:79-85.

14. Weaver JK, Chalmers J. Cancellous bone: its strength and changes with ageing and an evaluation of some methods for measuring its mineral content. J Bone Joint Surg [Am] 1966:48-A:289-99.

15. Burstein AH, Reilly DT, Martens M. Aging of bone tissue: mechanical properties. J Bone Joint Surg [Am] 1976;58-A:82-6.

16. Currey JD, Butler G. The mechanical properties of bone tissue in children. J Bone Joint Surg [Am] 1975;57-A:810-4.

17. McCalden RW, McGeough JA, Barker MB, Court-Brown CM. Age-related changes in the tensile properties of cortical bone: the relative importance of changes in porosity, mineralization and microstructure. J Bone Joint Surg [Am] 1993;75-A:1193-205.

18. Burstein AH, Zika JM, Heiple KG, Klein L. Contribution of collagen and mineral to the elastic-plastic properties of bone. $J$ Bone Joint Surg [Am] 1975;57-A:956-61.

19. Riggs BL, Wahner HW, Duun WL, et al. Differential changes in bone mineral density of the appendicular and axial skeleton with aging: relationship to spinal osteoporosis. J Clin Invest 1981;67: 328-35.

20. Linde F, Gøthgen CB, Hvid I, Pongsoipetch B. Mechanical properties of trabecular bone by a non-destructive compression testing approach. Eng Med 1988;17:23-9.

21. Neuman RE, Logan MA. The determination of collagen and elastin in tissues. J Biol Chem 1950;186:549-56.

22. Woessner JF. Determination of hydroxyproline in connective tissue In: Hall DA, ed. The methodology of connective tissue research. Vol. 1. Oxford, Joynson-Bruvvers Ltd, 1976:227-33.

23. Grant RA. Estimation of hydroxyproline by the AutoAnalyzer. $J$ Clin Pathol 1965;18:686.

24. Danielsen CC, Andreassen TT. Mechanical properties of rat tail tendon in relation to proximal-distal sampling position and age J Biomech 1988;21:207-12.

25. Panjabi MM, Krag M, Summers D, Videman T. Biomechanical time-tolerance of fresh cadaveric human spine specimens. J Orthop Res 1985;3:292-300.

26. Linde F, Sørensen HC. The effect of different storage methods on the mechanical properties of trabecular bone. J Biomech 1993;26: 1249-52.

27. Gong JK, Arnold JS, Cohn SH. Composition of trabecular and cortical bone. Anat Rec 1964;149:325-31.

28. Sharp DJ, Tanner KE, Bonfield W. Measurement of the density of trabecular bone. J Biomech 1990;23:853-7.

29. Linde F. Elastic and viscoelastic properties of trabecular bone by a compression testing approach. Dan Med Bull 1994;41:119-38.

30. Linde F, Hvid I, Madsen F. The effect of specimen geometry on the mechanical behaviour of trabecular bone specimens. J Biomech 1992; 25:359-68.

31. Goldstein SA, Matthews LS, Kuhn JL, Hollister SJ. Trabecular bone remodelling: an experimental model. J Biomech 1991;24 (Suppl 1):135-50.

32. Luo G, Cowin SC, Sadegh AM, Arramon YP. Implementation of strain rate as a bone remodelling stimulus. J Biomech Eng 1995;117: 329-38.

33. Scott JE. Proteoglycan-fibrillar collagen interactions. Biochem J 1988; 252:313-23.

34. Uldbjerg N, Danielsen CC. A study of the interaction in vitro between type I collagen and a small dermatan sulphate proteoglycan. Biochem J 1988;251:643-8.

35. Skerry TM, Suswillo R, EI Haj AJ, et al. Load-induced proteoglycan orientation in bone tissue in vivo and in vitro. Calcif Tissue Int 1990; 46:318-26.

36. Armstrong CG, Mow VC. Variations in the intrinsic mechanical properties of human articular cartilage with age, degeneration, and water content. J Bone Joint Surg [Am] 1982;64-A:88-94. 